\title{
Validity of virtual reality as a method of exposure in the treatment of test anxiety
}

\author{
Ivan Alsina-Jurnet, Cristina Carvallo-Beciu, ANd José Gutiérrez-Maldonado \\ University of Barcelona, Barcelona, Spain
}

\begin{abstract}
This is a validation study, aiming to explore the effectiveness of a set of virtual environments for producing emotionally significant responses in students with high levels of test anxiety in order to be able to implement them later in treatment. Twenty-one students agreed to take part, 11 with high test anxiety and 10 with low test anxiety. The virtual environments were prepared in chronological order: the student's home, then the metro, and finally the corridor and lecture hall where the examination takes place. The results showed that the high-testanxiety group presented higher levels of anxiety and depression than the low-test-anxiety group during exposure to the virtual environments. This study shows that virtual reality is able to provoke emotional responses in students with high test anxiety. This validation study should be followed up with treatment studies to evaluate the efficacy of virtual reality therapy for treating test anxiety.
\end{abstract}

Test anxiety has become a highly frequent problem in our society. Studies estimate that between $15 \%$ and $25 \%$ of students suffer from high levels of examination-related anxiety (Escalona \& Miguel-Tobal, 1992; Hill \& Wigfield, 1984). In Spain, a recent study among 28,463 university found high levels of test anxiety in $20.84 \%$ of them (Hernández, 2005) These findings are important not only because of the high number of students affected but also because of the negative consequences anxiety has on performance, leading, in the worst case scenario, to a sharp decline in students' academic results and to a serious restriction of their job prospects.

Test anxiety is usually conceived as a situation-specific personality trait (Spielberger \& Vagg, 1995). This means that students with this condition are predisposed to reacting with heightened anxiety in the face of situations that involve evaluation (Hodapp, Glanzmann, \& Laux, 1995). Liebert and Morris (1967) identified two fundamental components of test anxiety: worry and emotionality. Worry is a cognitive expression of concern with the possible negative consequences of poor performance, and emotionality refers to the activation of the autonomic nervous system in response to the stressful situation. Spielberger, González, Taylor, Algaze, and Anton (1978) also proposed worry and emotionality as the main components of the state anxiety experienced in exam situations.

Today it seems clear that students with high test anxiety present significantly poorer academic performance (Deffenbacher \& Kemper, 1974; King, Ollendick, \& Gullone, 1991; Sarason, 1963; Sarason, Davidson, Lighthall, Waite, $\&$ Ruebush, 1960; Topp, 1989). As a result, we find a high number of students who underachieve at school not because of learning problems or limited intellectual capacity, but simply because of their high level of anxiety. In the literature, worry has for some time been considered the main factor responsible for this underachievement (Deffenbacher, 1980; Morris \& Liebert, 1970; Mueller, 1992; Sarason, Sarason, Keefe, Hayes, \& Shearin, 1986; Seipp, 1991; Tobias, 1992). Worry refers to a set of thoughts related to the expectation of failure and its negative consequences, and subjects' fears of being less able than their peers (Hernández, Pozo, \& Polo, 1994); the result is that insufficient attention is paid to aspects that facilitate effective performance of the task (Wine, 1971). For its part, emotionality also interferes with the performance of the task, albeit indirectly, by triggering a large number of distracting thoughts (Spielberger \& Vagg, 1995).

The initial conceptions of test anxiety in terms of physiological and emotional responses guided research toward the use of methods to reduce the physiological activation. With time, the treatments began to adopt more cognitive approaches, or a combined approach (Ergene, 2003). Nonetheless, systematic desensitization is still the most widely used procedure for combating test anxiety (Crouse, Deffenbacher, \& Frost, 1985; Deffenbacher, Michaels, Michaels, \& Daley, 1980; Wilson, Omeltschenko, \& Yager, 1991).

Although the results obtained with systematic desensitization are highly satisfactory (Hembree, 1988; Spielberger \& Vagg, 1987), the multidimensional nature of test anxiety argues in favor of the integration of this technique inside wider-ranging treatment packages that may ultimately prove to be more effective. With this aim in mind, systematic desensitization has been used in conjunction with training in study habits (González 1976; Hembree, 1988 ) and with cognitive techniques (Goldfried, Linehan, \& Smith, 1978; Himle, Thyer, \& Papsdorf, 1982; Holroyd, 1976; Leal, Baxter, Martin, \& Marx, 1981).

I. Alsina-Jurnet, ivanalsina@ub.edu 
There is now some evidence that exposure treatment for anxiety disorders can be conducted using virtual reality technology. This technology integrates real-time computer graphics, body tracking devices, visual displays and other sensory inputs to immerse individuals in computergenerated virtual environments (Emmelkamp, 2005).

Virtual reality offers several advantages over in vivo exposure for the treatment of test anxiety. The logistics of in vivo exposure are complex, since examinations are held at specific times in the school year with long periods in between. With a virtual environment this is not the case: Tests can be staged at any time of year, and failure in a virtual examination has no bearing at all on students' results. It also makes it possible to repeat the exposure as often as necessary, facilitating overlearning, or repetition. Virtual reality also permits the design of different exam situations (for example, by adjusting the difficulty of the test, or introducing outside stressors such as late trains, faulty alarm clocks, and so on) which thus adapt the learning situation more closely to that of real life. Virtual reality also offers a series of advantages over imaginary exposure. Exposure to virtual environments is interactive and offers a uniform stimulus, whereas in imaginary exposure the patient may be excessively influenced by the therapist's storytelling. In fact, in some situations imaginary exposure is relatively ineffective, since the imaginative capacity of individuals varies widely. Finally, in a virtual environment the therapist knows exactly what the patient is seeing at all times.

In addition, virtual environments can be used in conjunction with conditioning procedures to model various aspects of anxiety (Baas, Nugent, Lissek, Pine, \& Grillon, 2004; Grillon, 2002), to understand aspects such as time course and susceptibility to pharmacologic intervention, or to evaluate neurophysiological abnormalities (Hong, Avila, Wonodi, McMahon, \& Thaker, 2005).

For a virtual environment to be effective as an exposure technique, it must produce anxiety responses. Although most researchers agree that the generation of emotion is an objective of virtual reality exposure (Baños et al., 2004; Klinger et al., 2005), some of the research carried out to date has assessed solely whether an environment proves effective for the treatment of a particular disorder. If the results of these trials are considered unsatisfactory, this does not necessarily mean that virtual reality is not an effective technique for the treatment of a particular disorder, merely that the environments designed may not be able to trigger an emotional response from the patient.

The first author to evaluate virtual environments in this way was Pertaub (Pertaub, Slater, \& Barker, 2002), who exposed 40 subjects to a small seminar situation. Each subject was required to give a 5-min talk in front of an audience of eight virtual characters seated opposite. There were three types of audience: The first remained neutral and unresponsive during the subject's talk, the second reacted positively and warmly, and the third reacted negatively, appearing hostile and bored. The results showed a significant positive correlation between participants' fear of public speaking and the fear they experienced while talking in front of positive and neutral audiences, but not in front of a negative audience. Furthermore, the

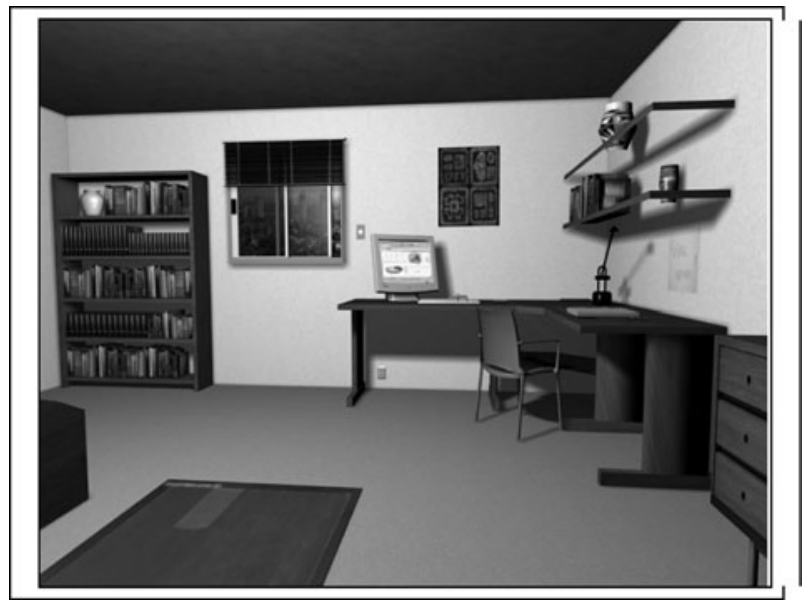

Figure 1. View of the bedroom.

group that spoke to the negative audience had experienced higher anxiety than the other groups, indicating that anxiety was influenced by the behavior of the audience. In a later study, the same research group (Slater et al., 2006) exposed 20 participants who were confident public speakers and 16 who were phobic either to an empty seminar room or to the same room populated by five avatars. People afraid of public speaking showed more anxiety when speaking in front of the virtual audience than in the empty room, whereas the nonphobic subjects showed no increase in signs of anxiety. Furthermore, both environments generated high anxiety levels in subjects who were afraid of public speaking. This suggests that the environments were able to trigger anxiety responses and were thus suitable for use in treating fear of public speaking.

In a similar research project, James, Chien Yu, Steed, Swapp, and Slater (2003) performed a study with 10 students which attempted to create social anxiety in virtual environments representing the London Underground service (known as the Tube) and a London pub. In the Tube situation, the characters behaved neutrally toward the subject,

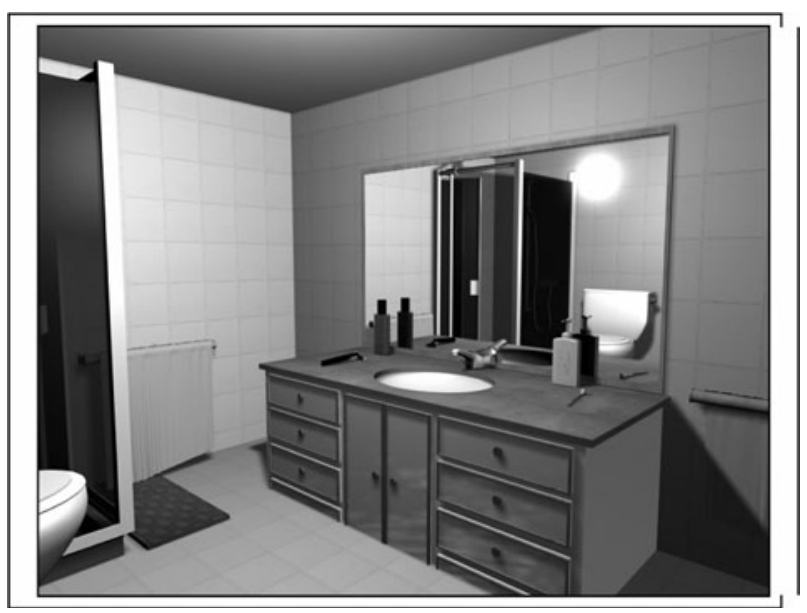

Figure 2. View of the bathroom. 
but in the pub scenario subjects were required to interact with the various characters, thus generating a higher degree of social involvement. The subjects displayed higher levels of anxiety in the socially demanding environment.

In the same year, Robillard's group (Robillard, Bouchard, Fournier, \& Renaud, 2003) explored whether it was possible to elicit anxiety responses in patients with fear of heights, spiders or enclosed spaces, by using virtual environments created with computer games. Thirteen subjects with phobia were exposed to environments presenting stimuli related to their specific phobia and 13 nonphobic subjects were exposed to one of the three environments created. Higher levels of subjective anxiety were found in the participants with phobia than in those without.

Finally, a study performed at the University of Barcelona (Gutiérrez-Maldonado, Ferrer-García, Caqueo-Urízar, \& Letosa-Porta, 2006) evaluated a set of virtual environments representing emotionally significant situations in patients with eating disorders. Thirty women were exposed for at least $25 \mathrm{~min}$ to five virtual environments: a kitchen with high-calorie food, a kitchen with low-calorie food, a restaurant with high-calorie food, a restaurant with lowcalorie food, and a swimming-pool. The virtual environments with high-calorie food provoked the highest levels of anxiety and depression, indicating that virtual reality is indeed a valid instrument for eliciting emotional responses in patients with eating disorders. Such virtual environments can also be used in conjunction with the BIAS software (Letosa-Porta, Ferrer-García, \& Gutiérrez-Maldonado, 2005) in order to assess body-image distortions and body satisfaction in different relevant situations.

The present study is part of a broader project in which exposure to virtual environments is used to treat and evaluate test anxiety. For these environments to be effective they must be able to elicit fear and anxiety (Krijn, Emmelkamp, Olafsson, \& Biemond, 2004). The first stage is a validation study, aiming to explore the effectiveness of a set of virtual environments for producing emotionally significant responses in students with high levels of test anxiety in order to be able to implement them later in treatment. The hypothesis is that students with high test anxiety will present higher levels of anxiety and depression when exposed to virtual environments than students with low test anxiety.

Some years ago, Knox (Knox, Schacht, \& Turner, 1993) advocated the use of virtual reality in place of imagination in the systematic desensitization technique, proposing the creation of virtual reality test anxiety machines (VIRTAMS) for use in schools to treat students with high test anxiety. This idea was initially developed by Max North (North, North, \& Crunk, 2004), who treated a 28 -year-old male with high test anxiety. The patient was exposed first to a virtual classroom and later to a virtual auditorium. The results of this case study suggested that virtual reality therapy can be effective in reducing self-reported test anxiety.

\section{METHOD}

\section{Subjects}

The initial sample, recruited via an online course on test anxiety and via advertisements in faculties at the University of Barcelona, comprised 240 university students, most of them women (78.8\%), between

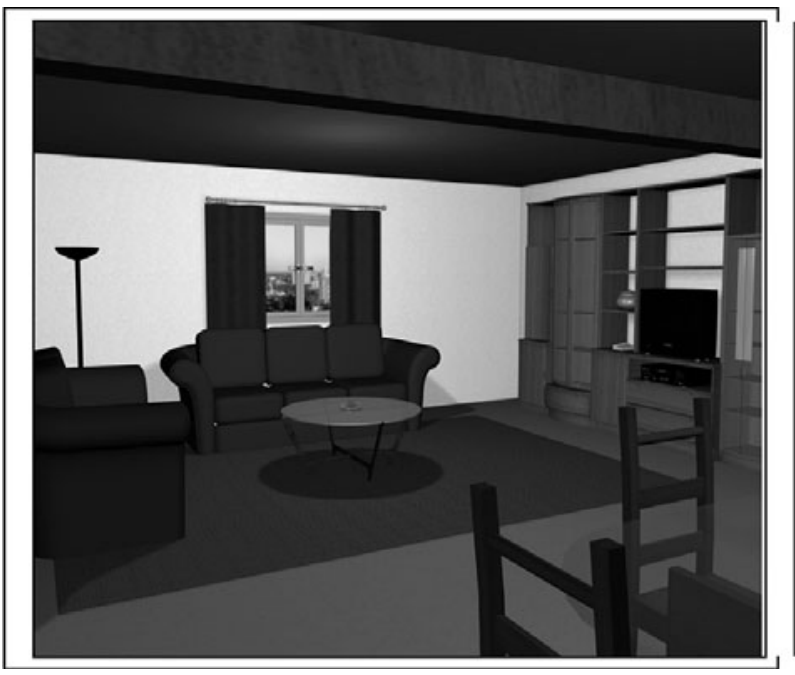

Figure 3. View of the dining room.

the ages of 19 and 38 (mean 23.83, SD 4.63). The Test Anxiety Inventory (TAI; Spielberger, 1980) was administered to assess subjects' degree of test anxiety. Students who presented high or low scores were contacted. Those with scores in or above the 70th percentile on the TAI were called for the high-test-anxiety group, and students with scores below the 30th for the low-test-anxiety group. Ultimately, 21 students agreed to take part, 11 with high test anxiety and 10 with low test anxiety. Seventeen were women ( $81 \%)$ and 4 men (19\%), with a mean age of 23.14 years $(S D 1.9$, range 19-27). The high-test-anxiety group comprised 10 women and 1 man with a mean age of 22.91 years $(S D$ 2.34 ), and the low-test-anxiety group comprised 7 women and 3 men with a mean age of 23.40 years $(S D 1.35)$.

\section{Instruments}

Hardware. The virtual environments were developed and displayed on 2-GHz Pentium IV computer with Windows 2000, 768 MB RAM, 60-GB hard disk, 19-in. monitor, and Hercules 3D Prophet 9700 PRO graphics cards with 128 MB DDR and AGP 8X. An I-visor DH-4400VP personal display was used with a resolution of $800 \times 600$ pixels and a visual field in diagonal of $31^{\circ}$, connected

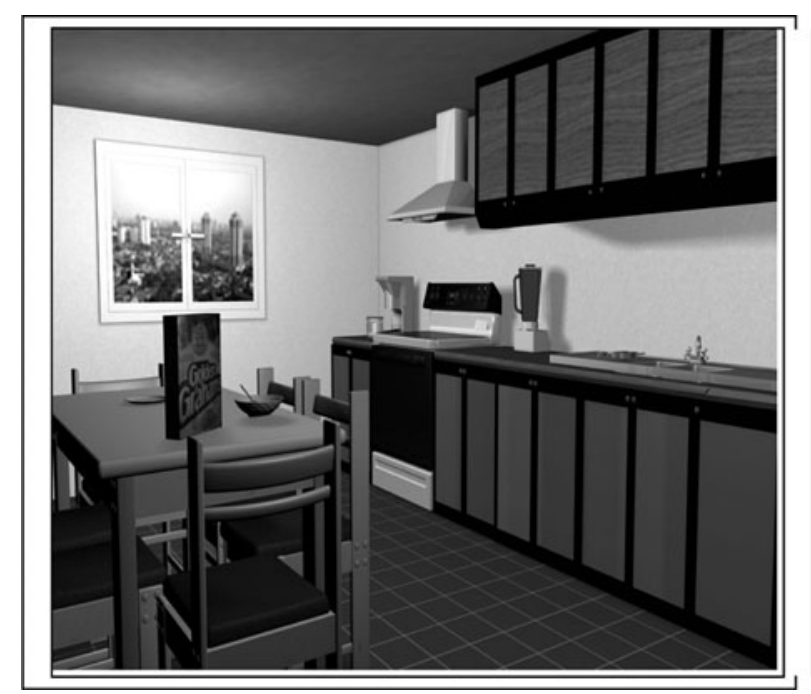

Figure 4. View of the kitchen. 


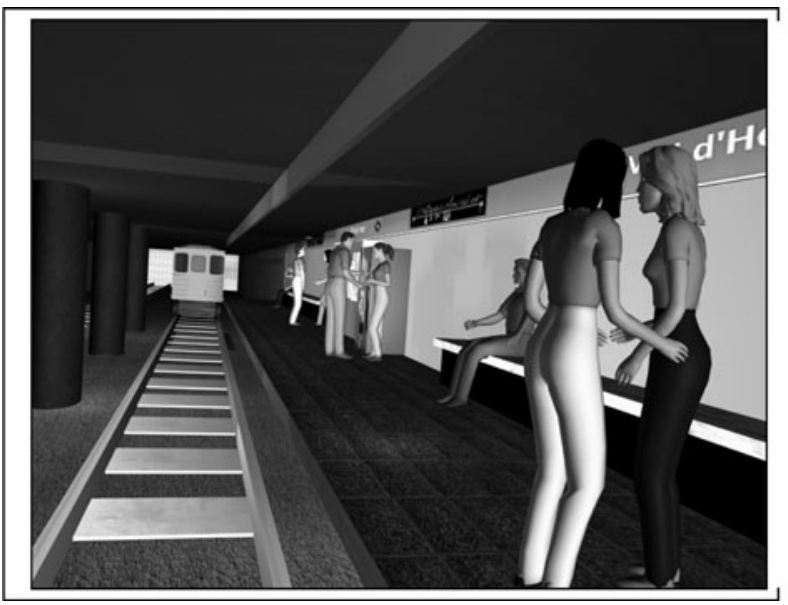

Figure 5. The Metro station.

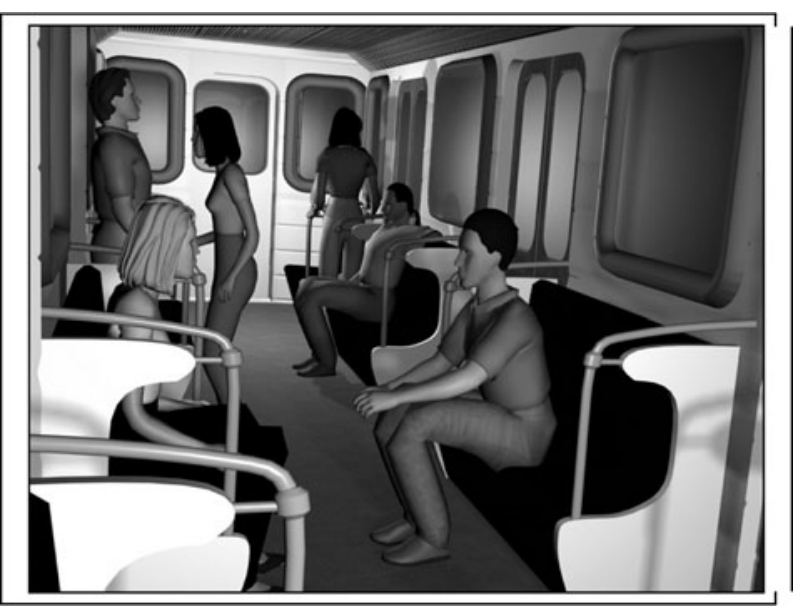

Figure 6. Inside the train.

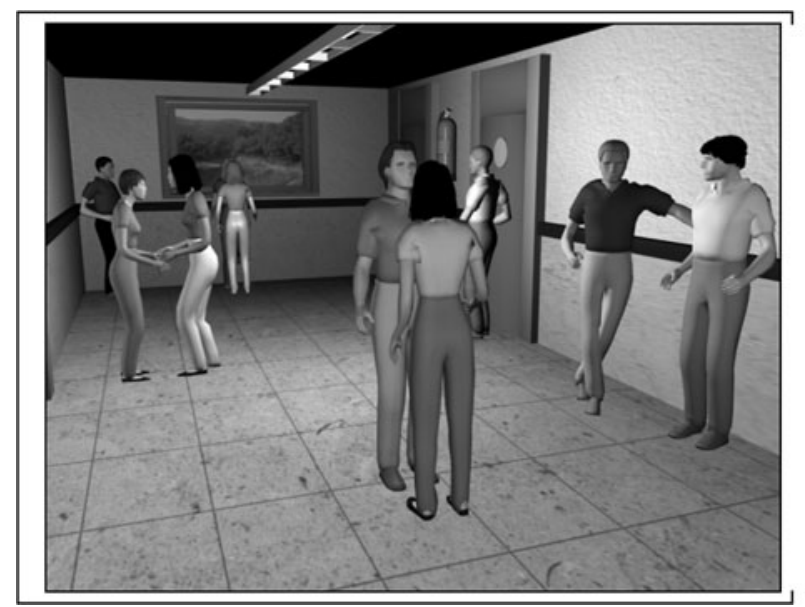

Figure 7. The hallway in the university. to an Intersense 3-DOF (degree of freedom) tracker that measured the position and movement of the head.

Software. To develop the virtual environments, tools of two kinds were used:

Modeling and animation tools. The scenarios, virtual elements, and animated 3-D objects were constructed with 3D Studio Max 6. The Poser 4 program was used to design the characters, which were animated with Character Studio 4.0. Adobe Photoshop 6.0 was used to create the textures and images.

Interactive development applications. Virtools Dev 2.5 (Educational Version) was used to combine the objects and characters created with the different graphic design tools, and to integrate them with textures and sound. It was also used to make the environments interactive and to facilitate browsing.

Virtual scenarios. The virtual environments were prepared in chronological order: the student's home, representing the day before and the morning of the examination; then the metro; and finally the corridor and lecture hall where the examination takes place. The situations and elements that comprise the environments were selected on the basis of a survey administered following a procedure that will be described later.

Home. The scenario includes a flat, with a bedroom, (Figure 1), a corridor, bathroom (Figure 2), dining room (Figure 3), kitchen (Figure 4), and hall. The first scene shows the student's bedroom at 11 o'clock on the night before the examination. In the room there is a desk with a textbook, and there are signs reminding him/her that there is an examination the next day. To increase the level of presence and to provoke the same emotional and cognitive reactions as in real situations, the students are able to carry out the same actions they would carry out on the day before a real examination: they can turn the lights on and off, open the windows, put on music, lie down on the bed, eat or drink, study, go to the bathroom, brush their teeth, have a shower, and so on. There are also clocks all over the house so that each student knows how much time is left to study or can decide when to go to bed.

This scenario is also used to represent the start of the examination day. The alarm clock rings at 7:30 a.m. As in the previous scenario, the students do all the things they would normally do; in addition, they now dress, prepare the belongings that they will take to the university, have breakfast, and so on.

Metro. This scenario represents part of the Barcelona underground system (Figure 5). The initial view shows the station entrance. Ahead of the student are the steps leading to the platform. Once there, the student hears the conversations of groups of other students waiting for the train. After a minute's wait the train arrives and the student gets on and sits down (Figure 6). During the journey, which lasts three stops, the student can study while other students talk about the examination they are about to take.

University. There are two scenarios at the university. In the first (Figure 7) the student is waiting in the hallway, outside the lecture room where the examination will take place. During the wait, he or she is surrounded by other students talking about the subjects, the examination, how they have prepared for it, and so on. After $5 \mathrm{~min}$, the lecturer arrives with the examinations and tells the students they can go in. The second scenario presents the lecture room where the examination will take place (Figure 8 ). The student is now seated and waits as the lecturer hands out the examinations. After the lecturer's instructions, the examination appears on the student's desk. Students have to answer 25 general knowledge questions. The format is multichoice, with four possible answers for each question.

Evaluation. We used the following standardized measures.

TAI (Test Anxiety Inventory; Spielberger, 1980). A self-report questionnaire designed to measure test anxiety as a situation-specific personality trait. The questionnaire comprises 20 items in which the student must indicate how often they experience the symptoms of anxiety before, during and after the examinations, on a 1- to 4-point Likert scale $(1=$ hardly ever, $4=$ almost always $)$. The TAI contains two subscales, of eight items each, which assess worry (cognitive aspects) and emotionality (physiological aspects). 


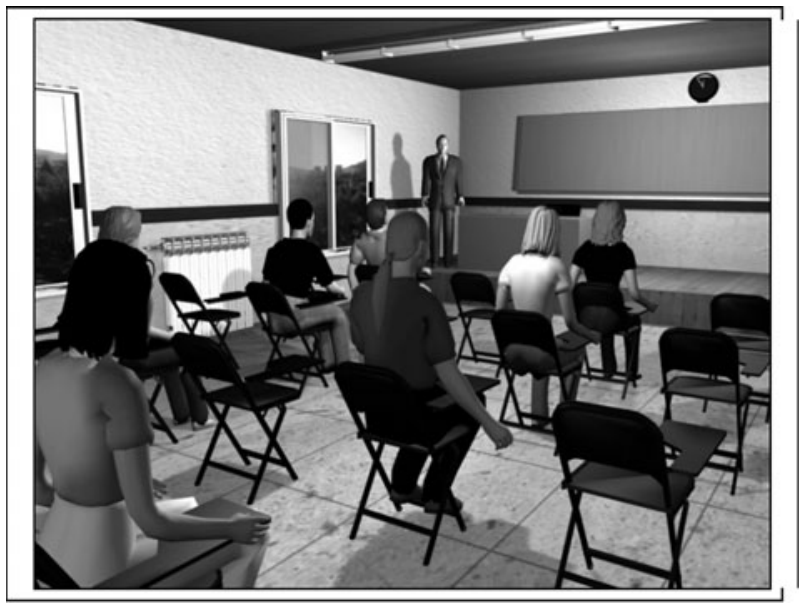

Figure 8. Inside the examination room.

STAI-S (State Anxiety Inventory; Spielberger, Gorsuch, \& Lushene, 1970). A self-report questionnaire that assesses state anxiety. This scale comprises 20 items scored on a Likert scale from 0 (not at all) to 3 (a great deal).

CDB (Barcelona Depression Questionnaire; Pérez, GutiérrezMaldonado, \& Ferrer, 2004). A self-report instrument for measuring changes in depressive state. It comprises 23 items, each one an adjective describing depressive symptoms (sad, frustrated, irritated, etc.); subjects put a cross on the line corresponding to their experience of this particular mood, ranging from I don't feel like this now to I feel like this now.

SUDS (Subjective Units of Discomfort Scale; Wolpe, 1969). Subjects indicate their maximum level of anxiety on a scale of 100 points $(0=$ zero and $100=$ extreme anxiety $)$.

\section{Procedure}

In the first stage of the study, the TAI (Spielberger, 1980) was administered to 240 university students in different academic years at 15 faculties at the University of Barcelona. The mean score obtained

Table 1

Situations Related to Examinations That Provoke Most Anxiety, in Descending Order of Frequency

\begin{tabular}{lc}
\hline \multicolumn{1}{c}{ Categories } & Frequency \\
\hline Comments of classmates & 79 \\
Studying the day before the examination & 67 \\
Bed time & 63 \\
Waiting in the hallway & 50 \\
The morning of the examination & 47 \\
Sitting in the examination room, waiting & 40 \\
The day before the examination & 38 \\
Exams being handed out & 22 \\
Reading the questions & 22 \\
Traveling to the examination & 21 \\
Going into the examination room & 19 \\
Going into the university & 19 \\
Revising on the way to the exam & 14 \\
Transport delay or breakdown & 11 \\
Lecturer late & 11 \\
Talking to classmates the day before & 6 \\
Not being able to get a good seat & 5 \\
Running out of time in the exam & 4 \\
Waiting for the train & 2 \\
Meeting classmates on the train & 2 \\
The possibility that the lecturer will talk to you & 1 \\
The possibility that the lecturer will look at you & 1 \\
\hline
\end{tabular}

on the TAI was 47.44 (SD 13.38, range 21-80). The mean scores were 16.12 (SD 5.57) on the worry subscale and 20.46 (SD 6.11) on the emotionality subscale.

To obtain information on the elements needed to make the environments clinically significant, we asked the sample to describe which examination-related situations and thoughts generated the most anxiety. After analysis of their responses, 22 specific categories were established (Table 1) and incorporated in the three previously designed environments.

After analyzing the TAI scores, students in the top 30\% and in the bottom $30 \%$ were contacted. Twenty-one agreed to participate in the study. Four males participated, three in the low-test-anxiety group and one in the high-test-anxiety group. Table 2 shows the scores on each subscale and on the total TAI scale.

In the next stage, the virtual environments were presented. Exposure to the virtual environments was individual. Subjects visited all the environments in a single session (the mean duration of the sessions, including exposure to the environments and administration of the questionnaires, totalled $90 \mathrm{~min}$ ). The procedure was double blind - that is, the researcher who administered the environments was unaware of the subject's TAI score, and students did not know their score or the aim of the research; they were told only that the study was designed to obtain information on students' behavior in exam situations, in order to prepare a treatment program. Before starting the session, the subjects were told that they would be shown a series of virtual environments simulating what students go through before and during an examination, starting with the previous evening and finishing with the examination itself. They were told that the exam consisted of a general knowledge test, which would be graded. They were asked to act as they would normally prior to and during an examination. Before starting the simulation of each scenario, they were told what it involved and what tasks they could perform.

After seeing each environment, the subjects were administered the STAI-S, the CDB, and the SUDS, and they were asked to identify the elements that had caused them the highest levels of anxiety.

\section{RESULTS}

A series of ANOVAs were performed on the designs of repeated measures ( 2 groups $\times 3$ environments) to compare state anxiety (STAI-S), subjective anxiety (SUDS), and depression mood (CDB) of the two groups of subjects after exposure to each of the virtual environments (home, underground, and university).

The results showed that the high-test-anxiety group presented higher levels of state anxiety (STAI-S) than the lowtest-anxiety group during exposure to the virtual environments $(F=24.431, p<.001)$; the difference between the two groups was equivalent in the three environments since no significant interaction was found between groups and situations $(F=1.192, p=.328)$. The effect of the situation was also significant $(F=10.641, p=.001)$, indicating that state anxiety varied according to the environment in which the students found themselves. The polynomial contrasts showed that the linear component of the effect of the situation $(F=0.377, p=.547)$ was not significant but that the quadratic component did reach significance $(F=20.714, p<.001)$. This finding indicates that the level of state anxiety in the two groups did not increase as the examination approached, but reached its peak during exposure in the Metro. Figure 9 shows these results.

The results obtained with the SUDS were similar to those found with the STAI-S (see Figure 10). There were significant differences between group $(F=18.091, p<.001)$; 
Table 2

Mean Scores of the Sample on the Test Anxiety Inventory (TAI) and on the Worry and Emotionality Subscales

\begin{tabular}{|c|c|c|c|c|c|c|}
\hline \multirow[b]{2}{*}{ Subjects } & \multicolumn{2}{|c|}{ TAI Total } & \multicolumn{2}{|c|}{ Worry } & \multicolumn{2}{|c|}{ Emotionality } \\
\hline & $M$ & $S D$ & $M$ & $S D$ & $M$ & $S D$ \\
\hline $\operatorname{All}(N=21)$ & 47.76 & 17.00 & 17.14 & 6.86 & 20.33 & 7.54 \\
\hline Low-test-anxiety group $(n=10)$ & 31.00 & 3.16 & 10.70 & 1.34 & 13.00 & 2.87 \\
\hline High-test-anxiety group $(n=11)$ & 63.00 & 5.80 & 23.00 & 3.43 & 27.00 & 1.95 \\
\hline
\end{tabular}

the high-test-anxiety group displayed higher levels of subjective anxiety during virtual exposure. These differences were found in the three environments, since the interaction between the group and the situations was not significant $(F=1.406, p=.272)$. The effect of the situation, however, was significant $(F=12.983, p<.001)$, indicating that the levels of subjective anxiety varied according to the environment. The polynomial contrasts showed that both the linear $(F=5.284, p=.034)$ and quadratic $(F=7.952, p=.011)$ components of the effect of the situation were significant.

Analyzing the scores obtained on the $\mathrm{CDB}$ also revealed significant differences $(F=9.738, p=.007)$ between the two groups in terms of the level of depression experienced during exposure to the environments. The interaction between groups and situations was not significant $(F=0.270$, $p=.767)$, indicating that the high-anxiety group presented a more depressed mood in all three scenarios. The effect of the situation was not significant, indicating that the levels of depression experienced by the students were similar in the three virtual environments. Figure 11 shows the levels of depression of the two groups in each of the three environments.

Finally, the scores on the virtual examination of each group were compared. The mean score of low-test-anxiety students was $7.080(S D$ 1.2), and that of high-test-anxiety students was $6.545(S D 1.37)$. Although the low-anxiety students performed better, the statistical analysis revealed that the difference was not significant $(t=0.941, p=.358)$.

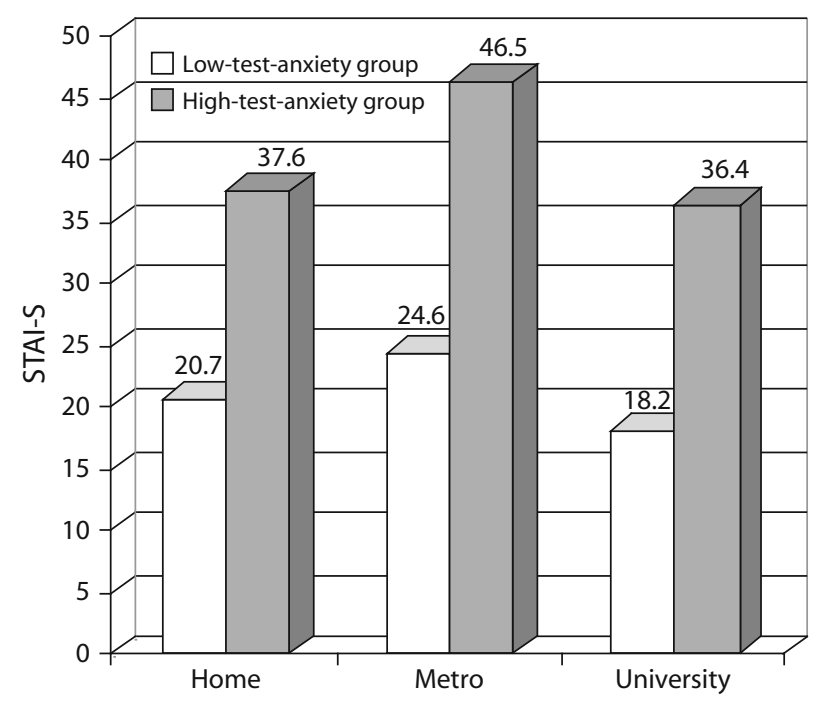

Figure 9. Mean scores of state anxiety measured with the STAI-S of the high- and low-test-anxiety groups after exposure to each of the three environments.

\section{DISCUSSION}

In the initial sample of 240 students, we obtained a mean TAI score of 47.44 ( $S D$ 13.38). The mean scores were 49.30 ( $S D$ 12.83) for women and 39.96 ( $S D$ 12.92) for men. These scores are higher than those obtained in previous studies, such as Spielberger et al. (1978) — which, in a sample of 1,449 U.S. university students, found mean scores of 42.79 $(S D$ 13.7) in women and 38.48 (SD 12.43) in men-or Bauermeister, Collazo, and Spielberger (1983) - which in a sample of 833 Puerto Rican students reported mean scores of 45.32 in women and 41.08 in men. A possible explanation for the higher scores in this study is that most of our students were taking part in a course on test anxiety, and so were likely to be particularly concerned by this problem.

One of the main problems with constructing clinically significant virtual environments is that standardized classifications of mental health disorders such as DSM-IV (American Psychiatric Association, 1994) or ICD-10 (World Health Organization, 1992) contain only phenomenological criteria and provide no guidelines to establish which environmental features are critical for a particular disorder (Huang \& Alessi, 1998). Thus, usually the subjective experience of the designers guided the choice of the elements included in the virtual environments. In contrast, in our study, to obtain information about the elements needed to make the environments clinically significant, we asked to a sample of university students which examination-related thoughts and situations generated the highest levels of anxiety.

But for these environments to be implemented in an exposure-mediated treatment program, their clinical significance must be demonstrated - that is, their ability to trigger emotional responses in students with high test anxiety. The results showed that there were significant between-group differences on the measures of anxiety and depression during exposure to the virtual environments. Thus, test anxiety students presented higher levels of subjective anxiety, state anxiety and depression mood than low test anxiety students. This suggests two things: first, that the environments trigger emotionally significant responses in high test anxiety students; second, that these responses are not caused merely by the use of virtual reality, since the low test anxiety students showed lower symptoms of anxiety or depression during exposure. These results are consistent with those of other validation studies of virtual environments, in which virtual reality proved effective in producing anxiety responses in subjects with higher scores on fear of public speaking (Pertaub, Slater, \& Barker, 2002; Slater et al., 2006), students exposed to socially demanding situations (James et al., 2003), patients with other specific 


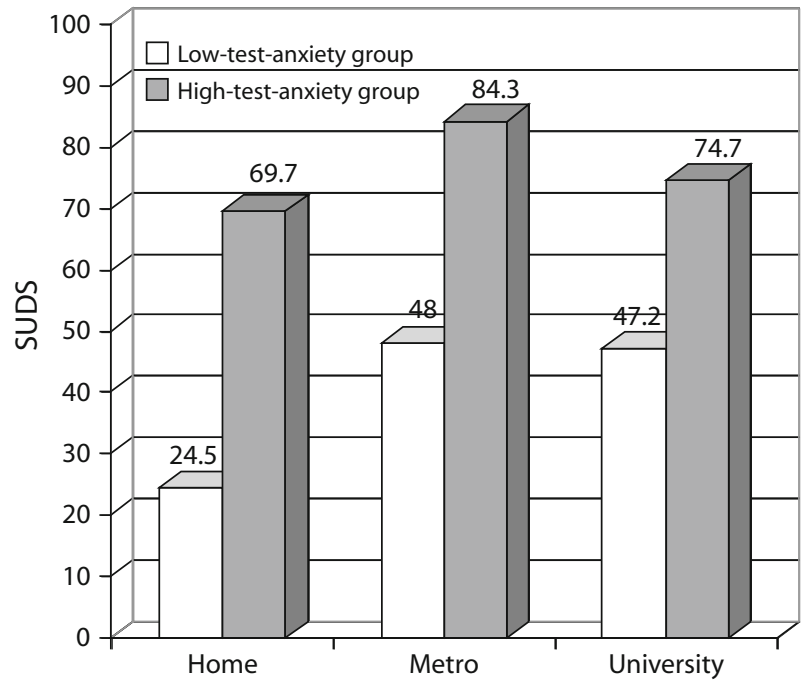

Figure 10. Mean scores of subjective anxiety (SUDS) of both groups in the three environments.

phobias (Robillard et al., 2003), and patients with eating disorders (Gutiérrez-Maldonado et al., 2006).

\section{CONCLUSIONS}

Virtual environments that reproduce the situations of preparing for and sitting an examination (revising, traveling to the exam center, etc.) are able to provoke higher levels of subjective and state anxiety, and higher levels of depression in high-test-anxiety students.

Even though the results suggest that the virtual environments can activate the emotional structure of the hightest-anxiety group and that the responses of both groups were similar to those that would be expected in a realworld exam, no comparison between groups was made in a neutral, emotionally nonsignificant environment. In future studies, we plan to compare the responses of high-

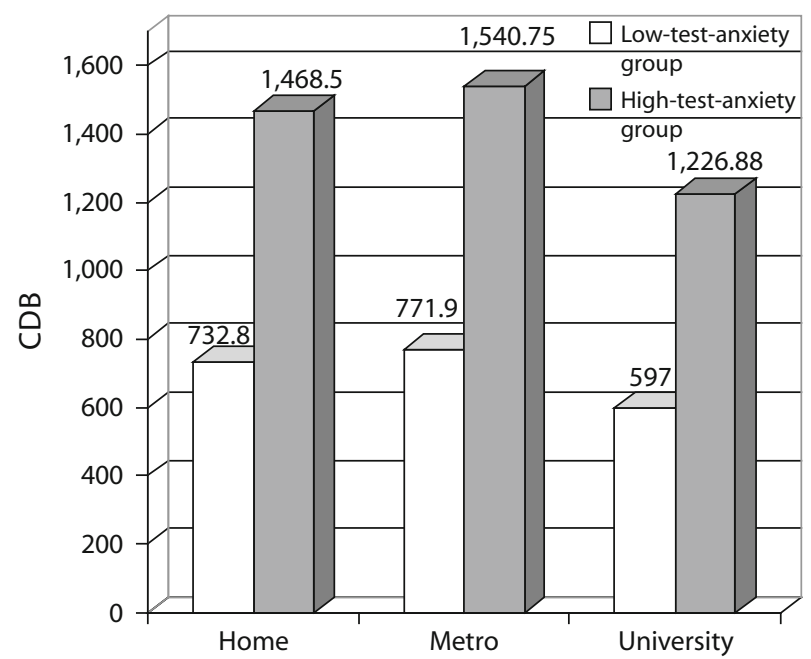

Figure 11. Mean scores of depressed mood (CDB) of both groups in the three environments. and low-test-anxiety students in a context unrelated to test anxiety. However, since trait anxiety and depression are not orthogonal to test anxiety, when exposed to a nonemotional virtual environment, high-test-anxiety students would be expected to experience higher levels of anxiety and depression mood than low-test-anxiety students. Nonetheless, we expect higher differences between the two groups of students in test anxiety environments.

It should be noted that the majority of the participants were women. Degrees of test anxiety differ according to gender; many studies have shown that females exhibit higher levels of test anxiety than males. In the study by Hernández (2005), the author found that the number of females with high levels of test anxiety can be from double to five-times the number of males. Therefore, further investigation is needed to evaluate the impact of virtual reality exposure on high-test-anxiety males.

This study demonstrates that virtual reality is a viable tool for the simulation of the exam situation and is able to provoke emotional responses in students with high test anxiety. In future controlled studies, we will evaluate the influence of these environments on the reduction of test anxiety.

\section{AUTHOR NOTE}

Correspondence related to this article may be addressed to I. AlsinaJurnet, Departamento de Personalidad, Evaluación y Tratamientos Psicológicos, Facultad de Psicología, Paseo Valle de Hebrón, 171, 08035 Barcelona, Spain (e-mail: ivanalsina@ub.edu).

\section{REFERENCES}

American Psychiatric Association (1994). Diagnostic and statistical manual of mental disorders (DSM-IV, 4th ed.). Washington, DC: American Psychiatric Association.

Bats, J. M., Nugent, M., Lissek, S., Pine, D. S., \& Grillon, C. (2004). Fear conditioning in virtual reality contexts: A new tool for the study of anxiety. Biological Psychiatry, 55, 1056-1060.

Baños, R. M., Botella, C., Alcañiz, M., Liaño, V., Guerrero, B., \& REY, B. (2004). Immersion and emotion: Their impact on the sense of presence. Cyberpsychology \& Behavior, 7, 734-741.

Bauermeister, J. J., Collazo, J. A., \& Spielberger, C. D. (1983). The construction and validation of the Spanish form of the Test Anxiety Inventory: Inventario de Auto-Evaluación Sobre Exámenes (IDASE). In C. D. Spielberger \& R. Díaz Guerrero (Eds.), Cross-cultural anxiety (Vol. 4, pp. 67-85). Washington, DC: Hemisphere.

Crouse, R. H., Deffenbacher, J. L., \& Frost, G. A. (1985). Desensitization for students with different sources and experiencies of test anxiety. Journal of College Student Personnel, 26, 315-318.

DEFFENBACHER, J. L. (1980). Worry and emotionality in test anxiety. In I. G. Sarason (Ed.), Test anxiety: Theory, research, and application (pp. 111-124). Hillsdale, NJ: Erlbaum.

DefFenbacher, J. L., \& Kemper, C. C. (1974). Counselling test-anxious sixth graders. Elementary School Guidance \& Counselling, 9, 22-29.

Deffenbacher, J. L., Michaels, A. C., Michaels, T., \& Daley, P. C. (1980). Comparision of anxiety management training and self-control desensitization. Journal of Counseling Psychology, 27, 232-239.

Emmelkamp, P. M. G. (2005). Technological innovations in clinical assessment and psychotherapy. Psychotherapy \& Psychosomatics, 74, 336-343.

ERGENe, T. (2003). Effective interventions on test anxiety reduction: A meta-analysis. School Psychology International, 24, 313-328.

Escalona, A., \& Miguel-Tobal, J. J. (1992). Ansiedad y rendimiento. In J. J. Miguel-Tobal (Ed.), Psicología de la ansiedad. Madrid: Mimeo.

Goldfried, M. R., Linehan, M., \& SMith, J. L. (1978). Reduction of test anxiety through cognitive restructuring. Journal of Consulting \& Clinical Psychology, 46, 32-39.

González, H. P. (1976). The effects of three treatment approaches on 
test anxiety, study habits, and academic performance. Unpublished master's thesis, University of South Florida, Gainesville.

GriLlon, C. (2002). Associative learning deficits increase symptoms of anxiety in humans. Biological Psychiatry, 51, 851-858.

Gutiérrez-Maldonado, J., Ferrer-García, M., Caqueo-Urízar, A., \& LetosA-Porta, A. (2006). Assessment of emotional reactivity produced by exposure to virtual environments in patients with eating disorder. Cyberpsychology \& Behavior, 9, 507-513.

Hembree, R. (1988). Correlates, causes, effects, and treatment of test anxiety. Review of Educational Research, 58, 47-77.

HernándeZ, J. M. (2005). Ansiedad ante los exámenes: Una evaluación de sus manifestaciones en los estudiantes universitarios españoles. In P.A.U. Education (Eds.), Un proyecto de atención al universitario en época de exámenes (Tech. Report, pp. 3-18). Barcelona: University of Barcelona.

Hernández, J. M., Pozo, C., \& Polo, A. (1994). Ansiedad ante los exámenes: Un programa para su afrontamiento de forma eficaz. Valencia: Promolibro.

Hill, K. T., \& Wigfield, A. (1984). Test anxiety: A major educational problem and what can be done about it. Elementary School Journal, 85, 105-126.

Himle, D. P., Thyer, B. A., \& PApsdorf, J. D. (1982). Relationships between rational beliefs and anxiety. Cognitive Therapy \& Research, 6, 219- 223.

Hodapp, V., Glanzmann, P. G., \& Laux, L. (1995). Theory and measurement of test anxiety as a situation-specific trait. In C. D. Spielberger \& P. R. Vagg (Eds.), Test anxiety: Theory, assessment, and treatment (pp. 47-59). Washington, DC: Taylor \& Francis.

Holroyd, K. A. (1976). Cognition and desensitization in the group treatment of test anxiety. Journal of Consulting \& Clinical Psychology, 44, 991-1001.

Hong, L. E., Avila, M. T., Wonodi, I., McMahon, R. P., \& Thaker, G. K. (2005). Reliability of a portable head-mounted eye tracking instrument for schizophrenia research. Behavior Research Methods, 37, 133-138.

Huang, M. P., \& Alessi, N. E. (1998). Current limitations into the application of virtual reality to mental health research. In G. Riva, M. D. Wiederhold, \& E. Molinari (Eds.), Virtual environments in clinical psychology and neuroscience (pp. 63-66). Amsterdam: IOS Press.

James, L. K., Chien Yu, L., Steed, A., Swapp, D., \& Slater, M. (2003). Social anxiety in virtual environments: Results of a pilot study. CyberPsychology \& Behavior, 6, 237-243.

King, N. J., Ollendick, T. H., \& Gullone, E. (1991). Test anxiety in children and adolescents. Australian Psychologist, 26, 25-32.

Klinger, E., Bouchard, S., Légeron, P., Roy, S., Lauer, F., CheMIN, I., \& Nugues, P. (2005). Virtual reality therapy versus cognitive behaviour therapy for social phobia: A preliminary controlled study. Cyberpsychology \& Behavior, 8, 76-88.

Knox, D., Schacht, C., \& Turner, J. (1993). Virtual reality: A proposal for treating test anxiety in college students. College Student Journal, 27, 294-296.

Krijn, M., Emmelkamp, P. M. G., Olafsson, R. P., \& Biemond, R. (2004). Virtual reality exposure therapy of anxiety disorders: A review. Clinical Psychology Review, 24, 259-281.

Leal, L. L., Baxter, E. G., Martin, J., \& Marx, R. W. (1981). Cognitive modification and systematic desensitization with test anxious high school students. Journal of Counseling Psychology, 28, 525-528.

Letosa-Porta, A., Ferrer-García, M., \& Gutiérrez-Maldonado, J. (2005). A program for assessing body-image disturbance using adjustable partial image distortion. Behavior Research Methods, 37, 638-643.

Liebert, R. M., \& Morris, L. W. (1967). Cognitive and emotional components of test anxiety: A distinction and some initial data. Psychological Reports, 20, 975-978.

Morris, L. W., \& Liebert, R. M. (1970). Relationship of cognitive and emotional components of test anxiety to physiological arousal and academic performance. Journal of Consulting \& Clinical Psychology, 35, 332-337.

Mueller, J. H. (1992). Anxiety and performance. In A. P. Smith \&
D. M. Jones (Eds.), Handbook of human performance (Vol. 3, pp. 127160). London: Academic Press.

North, M. M., North, S. M., \& Crunk, J. (2004). Virtual reality combats test anxiety: A case study report. Studies in Health Technology \& Informatics, 98, 278-80.

Pérez, B., Gutiérrez-Maldonado, J., \& Ferrer, M. (2004, April). Cuestionario de Depresión de Barcelona: Evaluación y curso de la depresión. Paper presented at the VII European Meeting and VI National Meeting of Psychological Assessment (EAPA-2004), Málaga, Spain.

Pertaub, D. P., Slater, M., \& Barker, C. (2002). An experiment on public speaking anxiety in response to three different types of virtual audience. Presence: Teleoperators \& Virtual Environments, 11, 68-78.

Robillard, G., Bouchard, S., Fournier, T., \& Renaud, P. (2003). Anxiety and presence during VR immersion: A comparative study of the reactions of phobic and non-phobic participants in therapeutic virtual environments derived from computer games. Cyberpsychology \& Behavior, 6, 467-476.

SARASON, I. G. (1963). Test anxiety and intellectual performance. Journal of Abnormal \& Social Psychology, 66, 73-75.

Sarason, I. G., Sarason, B. R., Keefe, D., Hayes, B. E., \& Shearin, E. N. (1986). Cognitive interference: Situational determinants and trait-like characteristics. Journal of Personality \& Social Psychology, 51, 215-226.

Sarason, S. B., Davidson, K. S., Lighthall, F. F., Waite, R. R., \& Ruebush, B. K. (1960). Anxiety in elementary school children. New York: Wiley.

SEIPP, B. (1991). Anxiety and academic performance: A meta-analysis of findings. Anxiety Research, 4, 27-41.

Slater, M., Pertaub, D. P., Barker, C., Clark, D., Phil, M., \& PHIL, D. (2006). An experimental study on fear of public speaking using a virtual environment. Cyberpsychology \& Behavior, 9, 627-633.

SPIElBerger, C. D. (1980). Test Anxiety Inventory: Preliminary professional manual. Palo Alto, CA: Consulting Psychologist's Press.

Spielberger, C. D., González, H. P., Taylor, C. J., Algaze, B., \& Anton, W. D. (1978). Examination stress and test anxiety. In C. D. Spielberger \& I. G. Sarason (Eds.), Stress and anxiety (Vol. 5, pp. 167191). New York: Wiley.

Spielberger, C. D., Gorsuch, R. L., \& Lushene, R. E. (1970). STAI manual. Palo Alto, CA: Consulting Psychologist's Press. [Spanish adaptation by Seisdedos, N. (1988). Madrid: Ediciones TEA.]

Spielberger, C. D., \& VAGG, R. (1987). The treatment of test anxiety: A transactional process model. In R. Schwarzer, H. M. Van der Ploeg, \& C. D. Spielberger (Eds.), Advances in test anxiety research (Vol. 5, pp. 179-186). Lisse: Swets \& Zeitlinger.

SPIElberger, C. D., \& VAGG, P. R. (1995). Test anxiety: A transactional process model. In C. D. Spielberger \& P. R. Vagg (Eds.), Test anxiety: Theory, assessment, and treatment (pp. 1-14). Washington, DC: Taylor \& Francis.

ToBIAs, S. (1992). The impact of test anxiety on cognition in school learning. In K. A. Hagtvet \& T. B. Johnsen (Eds.), Advances in test anxiety research (Vol. 7, pp. 18-31). Lisse: Swets \& Zeitlinger.

TopP, R. (1989). Effect of relaxation or exercise on undergraduates' test anxiety. Perceptual \& Motor Skills, 69, 35-41.

Wilson, F. R., Omeltschenko, L., \& Yager, G. G. (1991). Coping with tests stress: Microcomputer software for treatment of test anxiety. Journal of Behavior Therapy \& Experimental Psychiatry, 22, 131-139.

Wine, J. (1971). Test anxiety and direction of attention. Psychological Bulletin, 76, 92-104.

WolPE, J. (1969). The practice of behavior therapy. New York: Pergamon. World Health Organization (1992). The ICD-10 classification of mental and behavioural disorders: Clinical descriptions and diagnostic guidelines. Geneva: Author.

(Manuscript received July 24, 2006;

revision accepted for publication November 29, 2006.) 